Bull. Mater. Sci., Vol. 15, No. 1, February 1992, pp. 3-25. (C) Printed in India.

\title{
Material deformation and fracture under impulsive loading conditions
}

\author{
P RAMA RAO ${ }^{\dagger}$, S V KAMAT and G SUNDARARAJAN* \\ Defence Metallurgical Research Laboratory, Hyderabad 500258, India \\ ${ }^{\dagger}$ Department of Science and Technology, New Delhi 110016, India
}

\begin{abstract}
Engineering structures experience impulsive loads during the time of natural disasters like earthquakes, cyclones and collisions. The design of structures resistant to such natural disasters requires an understanding of the deformation and fracture behaviour of the materials constituting the structure under impulsive loading conditions. In this paper the various aspects of dynamic plastic deformation and fracture of common engineering materials are reviewed and contrasted with their behaviour under static loading conditions.
\end{abstract}

Keywords. Material deformation; fracture; impulsive loading; plastic deformation; high strain.

\section{Introduction}

Common engineering materials used as structural members and machine elements can fail to perform their intended functions because of their excessive elastic deformation, yielding or excessive plastic deformation or fracture. As a result, a full understanding of the nature of deformation (elastic and plastic) and fracture in common and newer engineering materials has to be developed as a part of the overall design strategy for structures and machine elements.

Many of the engineering structures are explicitly designed to meet the extreme static loading conditions that the structure may see during its service life. This design philosophy, though generally adequate, may not be appropriate under impulsive load conditions which the structure may encounter during earthquakes, cyclones, collisions or during other forms of natural disasters. Even to conclude that the design based on static loading conditions is adequate under impulsive loading conditions, the deformation and fracture behaviour of the engineering materials which make up the structures has to be evaluated under impulsive loading conditions.

Impulsive loading as opposed to static loading introduces a number of new and additional features which also will have a bearing on the material deformation and fracture behaviour. An impulsive load is usually characterized in terms of its peak load, the total duration of the loading and the rise, decay and residence time of the load. All these parameters are defined with respect to a typical, compressive impulsive load pulse in figure 1.

Whether the loading is static or dynamic is largely determined by the duration of the impulsive load $\left(t_{d}\right)$ in relation to the time it takes for the elastic wave from the loading point to traverse the full length of the structure $\left(t_{e}\right)$. Since elastic waves have a velocity in the range of $4 \mathrm{~km} / \mathrm{s}$ for many metallic materials, even to traverse a structure a metre long, the elastic wave takes only $250 \mu \mathrm{s}$. Thus, for loading duration

*For correspondence 


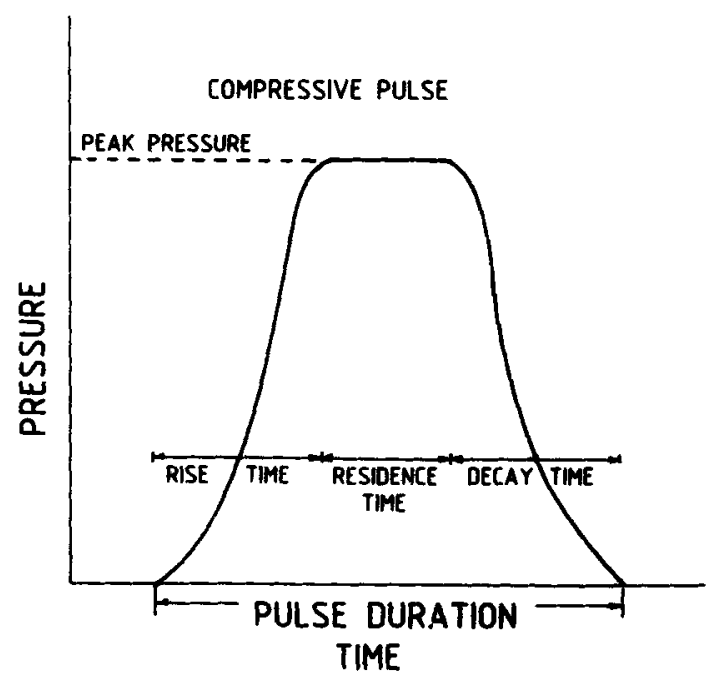

Figure 1. A schematic view of a typical compressive, impulsive load pulse.

$\left(t_{d}\right)$ greater than a few milliseconds, the applied load can be said to be feit uniformly and "instantaneously" by the whole structure leading to static loading conditions. However, the engineering structures are likely to experience impulsive loads of very short duration during natural disasters like earthquakes, collisions during cyclone or meteorite impact on the earth. In such cases, the stress analysis of the structures has to be carried out on the basis of propagation of elastic, plastic and shockwaves from the loading point. The magnitude of the peak load of the impulsive load largely determines the nature of the stress waves that emanate from the loading point. With increasing magnitude of the peak load, a natural progression from the elastic to the plastic to the shockwaves can be envisaged.

The objective of this paper is to highlight the behaviour of materials under impulsive loading conditions of very short duration. This type of loading causes the material to deform at very high strain rates of the order of $10^{4} \mathrm{~s}^{-1}$ or higher and further causes the pre-existing flaws in the structure to initiate and propagate in an environment of high loading rates in the range $10^{4} \mathrm{MPa} \sqrt{\mathrm{m}} / \mathrm{s}$ and greater. This paper will review the response of materials to such high loading rates. The next section $(\$ 2)$ reviews the salient features associated with high strain rate deformation of metallic materials while in $\S 3$, the subject of dynamic fracture toughness is briefly reviewed.

\section{Plastic deformation at high strain rates}

The need for evaluating the plastic deformation behaviour of materials at high strain rates exists because in many materials the plastic flow behaviour is strain rate-sensitive. This is illustrated in figure 2 wherein the variation of flow stress with strain rate is indicated for many typical metals and alloys (Briggs and Campbell 1972; Frantz and Duffy 1972; Klopp et al 1985; Follansbee 1986; Lindholm and Bessey 1986). Figure 2 clearly shows that the strain rate sensitivity (slope of the curves in figure 2) of all materials increases dramatically at strain rates beyond $10^{3} / \mathrm{s}$, i.e. in the dynamic loading regime. The effect is particularly dramatic in the case of bcc metals like iron 


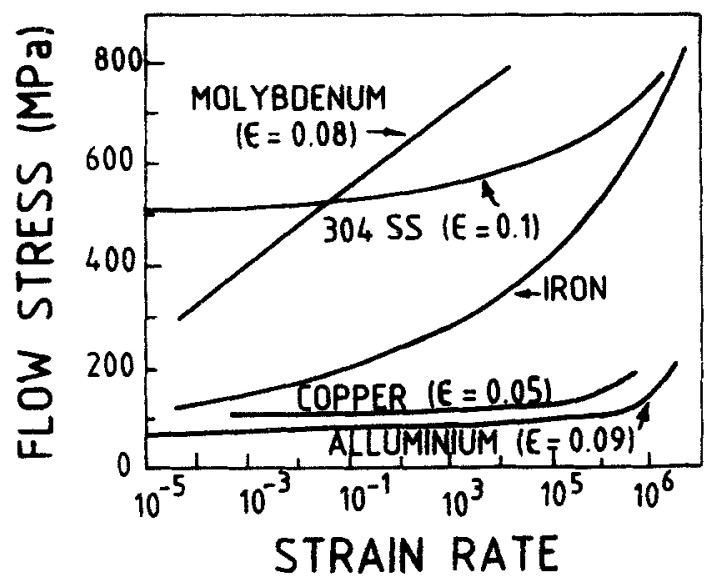

Figure 2. Strain rate dependence of the flow stress exhibited by typical metals and alloys.

and molybdenum. In this section the following aspects of high strain rate plastic deformation will be briefly reviewed:

(i) Test techniques for the characterization of high strain rate flow behaviour;

(ii) High strain rate deformation mechanisms; and

(iii) Typical test results.

\subsection{Test techniques}

The most common test techniques utilized to evaluate the material flow behaviour beyond $10^{2} / \mathrm{s}$ are discussed below.

(a) Split Hopkinson pressure bar (SHPB) technique: This technique utilizes two elastic bars that sandwich the specimen between them as illustrated in figure 3. A striker bar is propelled towards the incident bar usually by means of a gas gun. Upon impact, an elastic compressive wave propagates through the incident bar. A portion of it gets transmitted through the sample into the output bar. The hardness and cross-sectional area of the elastic bars in relation to the specimen are so chosen that the specimen undergoes plastic deformation. Strain gauges are fixed on the incident and the output bar to measure the elastic strains caused by the incident and the reflected waves as a function of time. If $\varepsilon_{I}(t)$ and $\varepsilon_{R}(t)$ are the incident and reflected strains measured on the incident bar, the plastic flow stress of the specimen $(\sigma(t))$ and the strain rate of deformation $(\dot{\varepsilon}(t))$ can be obtained as (Hopkinson 1914; Lindholm 1971; Follansbee 1985)

$$
\begin{aligned}
\sigma(t) & =E \cdot\left(A_{0} / A\right) \cdot\left(\varepsilon_{I}+\varepsilon_{R}\right), \\
\dot{\varepsilon}(t) & =2 C_{0} \varepsilon_{R}(t) / L, \\
\varepsilon & =\ln L / L_{0},
\end{aligned}
$$

In equations (1) to (3), $E$ is the Young's modulus of the bar, $C_{0}$ is the speed of the elastic wave in the elastic bars, $A_{0}$ is the cross-sectional area of the bar, $A$ is the cross-sectional area of the specimen and $L$ and $L_{0}$ are the final and initial length of 


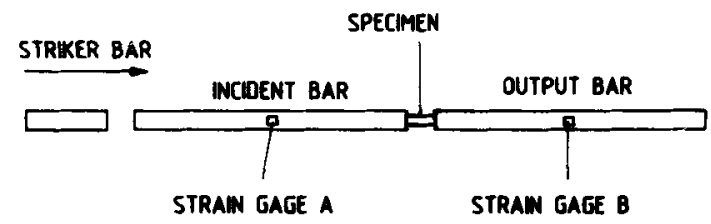

Figure 3. Typical configuration of bars used in a split Hopkinson pressure bar technique.

the specimen. The SHPB technique described above evaluates the high strain rate $\sigma-\varepsilon$ relation under compressive mode conditions. However, with some modifications, SHPB technique can be used to test samples in torsion and tension as well (Baker and Yew 1966; Lindholm and Yeakley 1968).

(b) Expanding ring test technique: In this test, the specimen in the form of a ring is made to experience a sudden radial acceleration as a result of electromagnetic loading or an explosive detonation (Niordson 1965; Hoggatt and Recht 1969). The ring very quickly becomes a free flying body expanding radially and decelerating due to its own circumferential stress. Under such conditions, the hoop stress $(\sigma)$ and $\operatorname{strain}(\varepsilon)$ are given by,

$$
\begin{aligned}
& \sigma=\rho \cdot R \cdot\left(d^{2} R / \mathrm{d} t^{2}\right), \\
& \varepsilon=\ln R / R_{0},
\end{aligned}
$$

where $R$ and $R_{0}$ are the current and initial radius of the ring, $\rho$ is the ring density and $t$ the time. Thus, if $R$ is measured as a function of time both $\sigma$ and $\varepsilon$ can be computed. Either high speed photography or laser velocity interferometer, is used to monitor either the ring displacement $(\mathrm{d} R)$ or the ring velocity $(\mathrm{d} R / \mathrm{d} t)$ itself. An advantage of this technique is that the tests can be conducted up to fracture.

(c) The Taylor cylinder test: This technique was originally developed by Taylor (1948) to determine the dynamic yield stress of a material. In this technique, the test material in the form of a cylinder (initial length $L_{0}$ ) is impacted against a rigid plate, much harder than the cylinder, at a velocity $V$. The cylinder 'mushrooms' during impact. If $L_{f}$ is the final length of the cylinder and $H$ the final length of the undeformed portion of the cylinder after impact, the dynamic yield strength $\left(\sigma_{y d}\right)$ is obtained as (Taylor 1948).

$$
\sigma_{y \mathrm{~d}}=\frac{\rho V^{2}}{2} \frac{L_{0}-H}{L_{0}-L_{f}} \frac{1}{\ln \left(L_{0} / H\right)} .
$$

The corresponding mean strain rate $(\dot{\varepsilon})$ is given by,

$$
\dot{\varepsilon}=V / 2 \cdot\left(L_{0}-H\right) \text {. }
$$

The Taylor method can be utilized to obtain the entire flow stress-strain behaviour if test data are used in conjunction with two-dimensional finite difference codes utilizing an elastic-plastic constitutive equation taking into account the workhardening effects (Hawkyard et al 1968; Wilkins and Guinan 1973).

(d) Pressure-shear plate impact testing: This is a relatively new technique which allows strain rates as high as $10^{7} / \mathrm{s}$ to be achieved (Li 1982; Klopp 1982; Klopp et al 
1985). The test is performed by impacting a thin, soft specimen plate with a hard, elastic flyer plate inclined at an angle. The thin specimen is backed by a thick elastic anvil plate thereby creating a state of high pressure and high strain rate in the specimen. The stresses in the plastically deforming specimen can be inferred by measuring the initial normal component of the flyer plate velocity $\left(V_{0}\right)$ and the transverse particle velocity at the rear surface of the anvil $\left(V_{\mathrm{fs}}\right)$. Usually laser interferometer is used to measure $V_{\mathrm{fs}}$. Once $V_{0}$ and $V_{\mathrm{fs}}$ are known the shear flow stress $(\tau)$ and the shear strain rate $(\dot{\gamma})$ can be obtained as

$$
\begin{aligned}
& \tau=0.5 \cdot \rho C_{2} \cdot V_{\mathrm{fs}}, \\
& \dot{\gamma}=V_{0}-V_{\mathrm{fs}} / h,
\end{aligned}
$$

where $\rho C_{2}$ is the shear acoustic impedance of the anvil material and $h$, the specimen thickness.

(e) The dynamic indentation (DI) technique: DI is a novel technique developed at DMRL to characterize the high strain rate $\left(10^{4} / \mathrm{s}\right)$ flow behaviour of ductile materials (Tirupataiah and Sundararajan-1991). In this technique, a very hard ball is allowed to impact the test specimen over a range of impact velocities $(V)$ using a single stage gas gun (figure $4 a$ ). The craters that are formed by such impacts (figure $4 b$ ) are

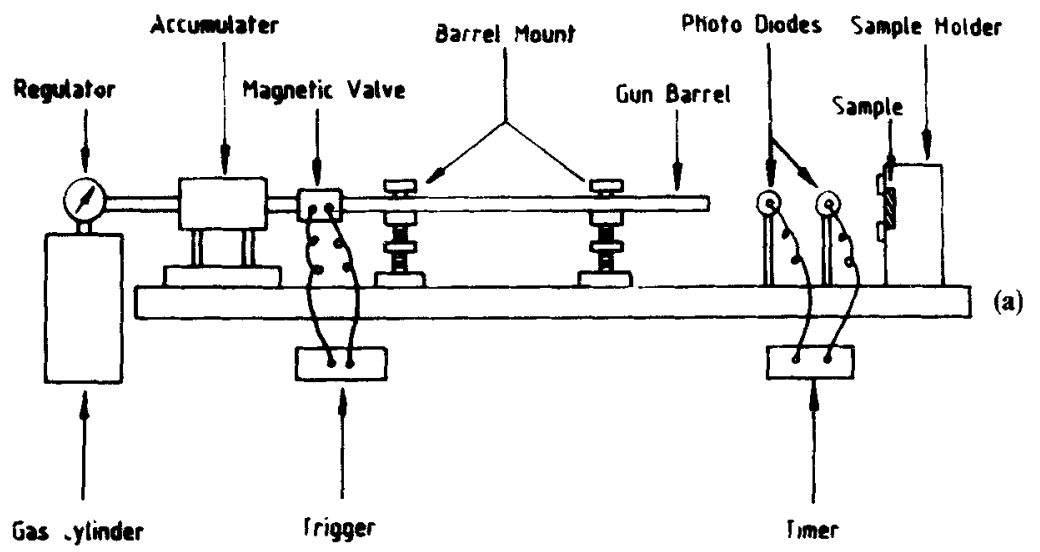

BRINELL INDENTATION

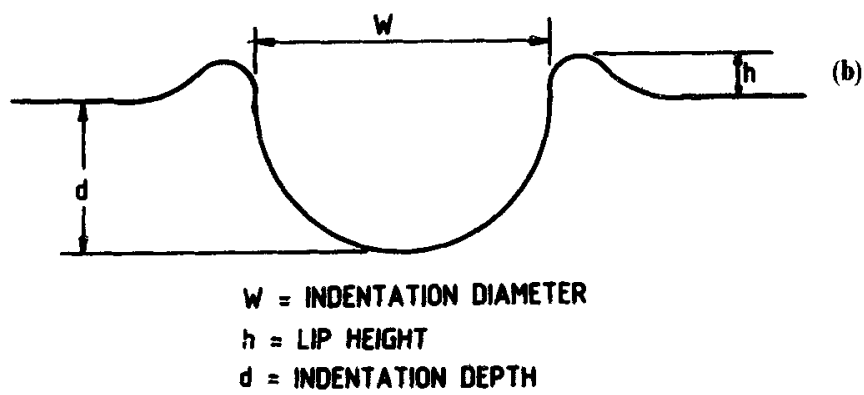

Figure 4. (a) A schematic view of the gas gun used for propelling spherical balls in the DI technique. (b) Profile of the typical crater formed during dynamic indentation with a spherical ball. 
examined and their diameter $(W)$ and hence volume $(U)$ determined. The dynamic hardness $\left(H_{d}\right)$ of the test material and the corresponding average strain $\left(\varepsilon_{\mathrm{av}}\right)$ and strain rates $\left(\dot{\varepsilon}_{\mathrm{av}}\right)$ are then obtained as (Tirupataiah and Sundararajan 1991),

$$
\begin{aligned}
H_{d} & =0.5 \mathrm{mV}^{2} / U, \\
\varepsilon_{\mathrm{av}} & =0.1(W / r), \\
\dot{\varepsilon}_{\mathrm{av}} & =1.28 W H_{d}^{1 / 2} / r^{2} \rho_{b}^{1 / 2},
\end{aligned}
$$

where $r$ is the ball radius and $\rho_{b}$ its density. Usually WC $\left(\rho_{b}=15150 \mathrm{~kg} / \mathrm{m}^{3}\right.$; $H \simeq 20 \mathrm{GPa}$ ) is used as the spherical projectile. By carrying out the DI test at different velocities (and hence different $W$ ), $H_{d}$ can be obtained at different strain $\left(\varepsilon_{\mathrm{av}}\right)$ values. By dividing $H_{d}$ by the constraint factor (which has to be determined experimentally), the dynamic flow stress $(\sigma)$ - strain $(\varepsilon)$ curve can then be obtained.

(f) Comparison of test techniques: We have described the above 5 different test techniques for characterizing the high strain rate flow behaviour of materials. Table 1 compares the advantages and the disadvantages of these techniques.

\subsection{Deformation mechanisms at high strain rates}

This paper is concerned with high strain rate deformation wherein diffusion-controlled thermal recovery is unlikely. Therefore, the relevant deformation mechanisms can be listed as (a) athermal deformation, (b) thermally-activated deformation and (c) viscous deformation. All these three deformation mechanisms can be understood by considering a dislocation travelling in the glide plane under the action of an impulsive stress. The dislocation in general comes across three types of barriers to it. The first is the large-range or athermal barrier by which it is meant that the barrier strength or its

\begin{tabular}{|c|c|c|c|c|c|c|}
\hline Test technique & $\begin{array}{l}\text { Strain rate } \\
\text { range }\left(s^{-1}\right)\end{array}$ & $\begin{array}{l}\text { Sophistication of } \\
\text { technique }\end{array}$ & $\begin{array}{l}\text { Uniformity } \\
\text { of } \dot{\varepsilon} \text { as a } \\
\text { function } \\
\text { of time }\end{array}$ & $\begin{array}{l}\text { Can test } \\
\text { go upto } \\
\text { fracture }\end{array}$ & $\begin{array}{l}\text { Spatial } \\
\text { uniformity } \\
\text { of stress }\end{array}$ & $\begin{array}{l}\text { Does it } \\
\text { simulate } \\
\text { impact }\end{array}$ \\
\hline 1. SHPB & $10^{2}-10^{5}$ & $\begin{array}{l}\text { Sophisticated with } \\
\text { regard to experimetal } \\
\text { set up and analysis }\end{array}$ & $\begin{array}{l}\text { Varies by } \\
\text { a factor of } \\
\text { two }\end{array}$ & No & Very good & No \\
\hline $\begin{array}{l}\text { 2. Expanding } \\
\text { ring }\end{array}$ & $10^{2}-10^{4}$ & $\begin{array}{l}\text { Highly sophisticated } \\
\text { in terms of measure- } \\
\text { ment }\end{array}$ & Not uniform & Yes & $\begin{array}{l}\text { Very good } \\
\text { if ring is } \\
\text { thin }\end{array}$ & No \\
\hline 3. Taylor test & $10^{2}-10^{5}$ & $\begin{array}{l}\text { Simple if only } \\
\text { yield stress is to be } \\
\text { measured }\end{array}$ & $\begin{array}{l}\text { Decreases } \\
\text { with incre- } \\
\text { asing time }\end{array}$ & No & Not good & No \\
\hline $\begin{array}{l}\text { 4. Pressure-shear } \\
\text { plate impact } \\
\text { test }\end{array}$ & $10^{4}-10^{7}$ & $\begin{array}{l}\text { Highly sophisticated } \\
\text { with regard to test } \\
\text { measurement }\end{array}$ & Uniform & No & Very good & No \\
\hline 5. DI technique & $10^{3}-10^{5}$ & Very simple & $\begin{array}{l}\text { Varies by a } \\
\text { factor of two }\end{array}$ & No & Not good & Yes \\
\hline
\end{tabular}
extent is so large that thermal activation cannot aid the dislocation in overcoming

Table 1. Advantages and disadvantages of various high strain rate techniques. 
it. If the dislocation motion is controlled by these athermal barriers then the deformation is considered to be athermal, i.e. independent of temperature except for the effect of temperature on elastic modulus and also insensitive to strain rate. The athermal component of the flow stress $\left(\sigma_{\text {ath }}\right)$ is obtained from,

$$
\sigma_{\mathrm{ath}}=\alpha \cdot G b \rho_{t}^{1 / 2},
$$

where $\alpha$ is the orientation factor $(\sim 1), G$ the shear modulus, $b$ the burgers vector and $\rho_{t}$ the total dislocation density. Examples of athermal barriers are long-range stress field felt by the glide dislocation due to other dislocations (for which equation (13) is valid), dispersoids in dispersion-strengthened alloys and solutes with significant size and modulus mismatch in solid solution alloys.

The thermally-activated mechanism becomes important in the case of short-range barriers to dislocation motion which can be overcome by a combination of stress and thermal fluctuation. The constitutive equation for this type of mechanism can be shown to be (Follansbee and Kocks 1988)

$$
\sigma_{\mathrm{th}}=\hat{\sigma}_{\mathrm{th}}\left[1-\left(\frac{K T \ln \dot{\varepsilon}_{0} / \dot{\varepsilon}}{G b^{3} g_{0}}\right)^{1 / q}\right]^{1 / p} .
$$

In (14), $\hat{\sigma}_{\text {th }}$ is the thermal component of the mechanical threshold, $\dot{\varepsilon}_{0}$ is a constant $\left(\simeq 10^{7} / \mathrm{s}\right), g_{0}$ is the normalized activation energy required for overcoming the obstacle, $T$ the absolute temperature, $\sigma_{\mathrm{th}}$ the thermal component of the flow stress at strain rate $\dot{\varepsilon}$ and temperature $T$ and $p$ and $q$ are constants which define the force-distance profile of the obstacle (Kocks et al 1975). Examples of thermally-activated barriers are Peierls-Nabarro lattice resistance, particularly in bec and covalent materials, precipitates in precipitation-hardened systems and attractive cutting of forest dislocations by the mobile dislocations.

The athermal and thermally-activated mechanisms can be combined to give the flow stress $\left(\sigma_{f}\right)$ of the material as

$$
\sigma_{f}=\sigma_{\mathrm{ath}}+\sigma_{\mathrm{th}}
$$

where $\sigma_{\text {ath }}$ is given by (13) and $\sigma_{\mathrm{th}}$ by (14). From (14), it is obvious that when either $T=0$ or $\dot{\varepsilon}=\dot{\varepsilon}_{0}$, the term within the parenthesis becomes 1 and thus (15) simplifies to

$$
\sigma_{f}=\sigma_{\mathrm{ath}}(T=0)+\hat{\sigma}_{\mathrm{th}}=\hat{\sigma} .
$$

The term $\hat{\sigma}$ in (16) represents the total mechanical threshold. If the applied stress on the dislocation exceeds $\hat{\sigma}$, then all the barriers (athermal and thermal) become transparent to the dislocation and it goes through the material in "free-flight" mode. Under such conditions, the only resistance to the dislocation motion is that due to the lattice phonons (or electrons at temperatures of $20 \mathrm{~K}$ and below). In this regime of viscous drag the constitutive equation becomes (Kumar et al 1968; Muller 1971),

$$
\sigma_{\mathrm{vis}}=\sigma_{\mathrm{ath}}+\frac{B}{\rho_{m} b^{2}} \cdot \dot{\varepsilon}
$$

where $B$ is the phonon viscous drag coefficient and $\rho_{m}$ the mobile dislocation density. An important validity condition for (17) is that $\sigma_{\text {vis }}>\hat{\sigma}$.

The manner in which the three deformation mechanisms discussed above combine is schematically illustrated in figure 5 . In this figure, the variation of the flow stress normalized by the shear modulus as a function of strain rate (top figure) and the 


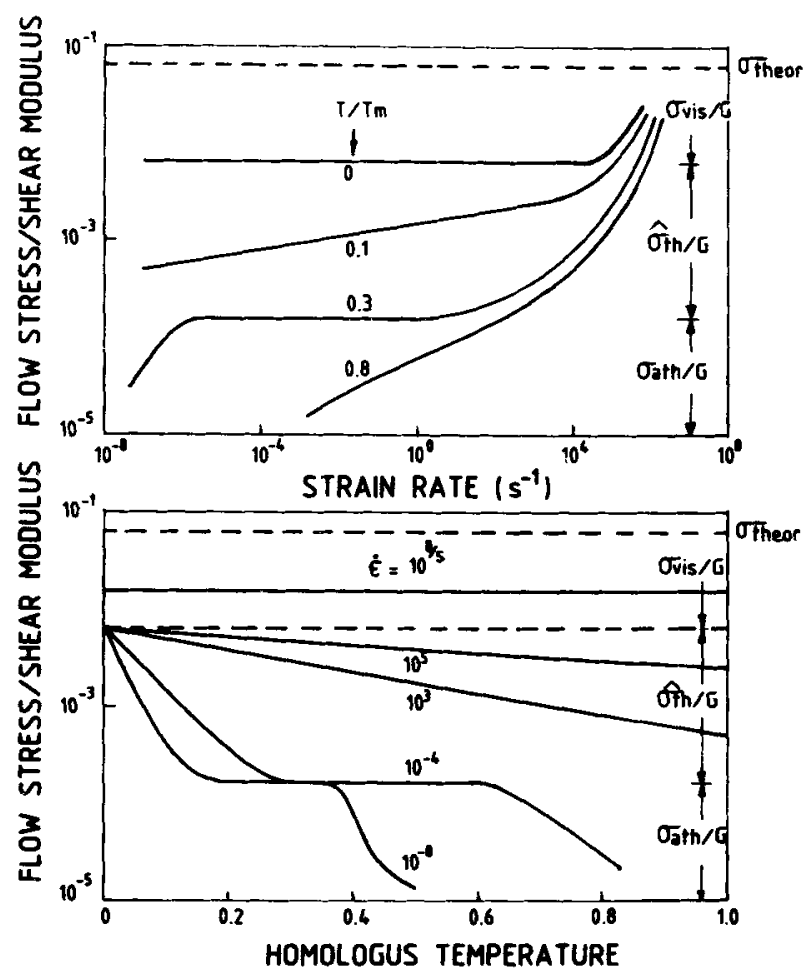

Figure 5. Typical Lindholm maps indicating the variation of the flow stress normalized by the shear modulus with homologous temperature and strain rate.

homologous temperature (i.e. temperature normalized by the melting point; bottom figure) are illustrated. The plateau region in both the figures represents the athermal flow stress. Thermal recovery is responsible for flow stress being lower than the athermal value at low strain rates and high temperatures. The dramatic increase in flow stress beyond a strain rate of $10^{4} \mathrm{~s}^{-1}$ is due to the transition from thermally activated to the viscous deformation mechanism. It is also interesting to note that in the viscous regime, the normalized flow stress depends negligibly on temperature. The dominance of the various deformation mechanisms in a strain rate-homologous temperature space can be better appreciated using a simplified diagram shown in figure 6. This figure clearly shows the importance of creep and thermal recovery mechanisms at low strain rates and high temperatures while in contrast, the viscous drag mechanisms become dominant at very high strain rates. The athermal and thermally-activated mechanisms become rate-controlling over a broad range of strain rate and temperature.

\subsection{Typical test results}

In this subsection, the high strain rate flow behaviour of a variety of materials will be presented and discussed. Figures 7 a to $7 \mathrm{c}$ illustrate the high strain rate $\left(\sim 10^{4} / \mathrm{s}^{1}\right)$ flow behaviour of annealed copper, copper- $20 \mathrm{Zn}$ alloy and $\mathrm{Cu}-5 \cdot 3 \mathrm{Al}$ alloy respectively, as obtained using the DI technique (Tirupataiah and Sundararajan 1990; Tirupataiah and Sundararajan 1991). The dynamic hardness $\left(H_{d}\right)$-strain curves obtained experi- 


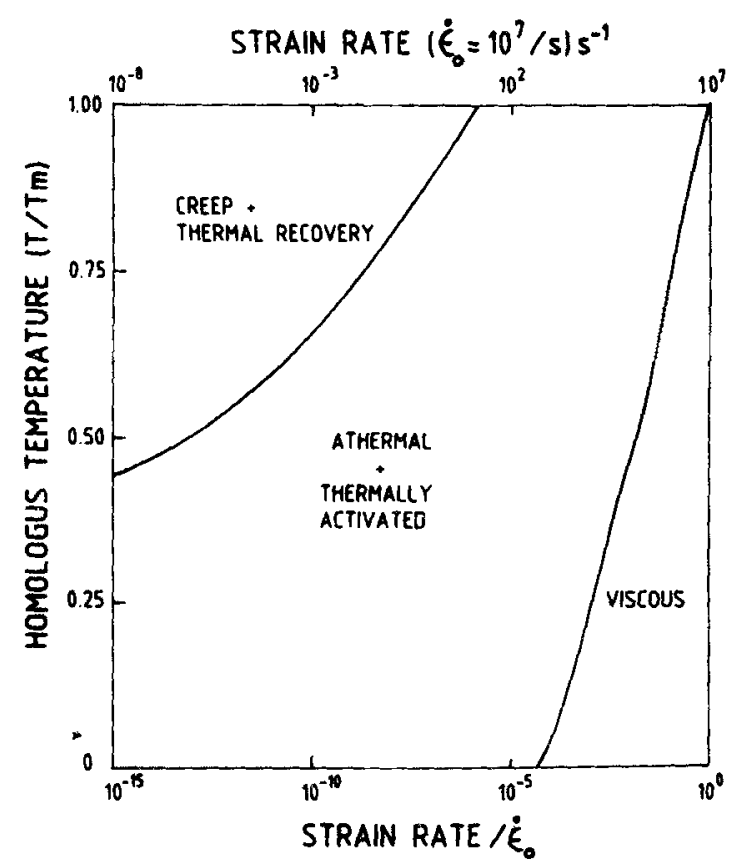

Figure 6. A schematic diagram indicating the dominance of the various deformation mechanisms in a homologous temperature-strain rate space.

mentally (filled circles) have been converted to equivalent uniaxial dynamic flow stress $\left(\sigma_{d}\right)$-strain curves using the constraint factor $(c)$. A comparison of the dynamic and static flow stress-strain curves in the case of $\mathrm{Cu}, \mathrm{Cu}-20 \mathrm{Zn}$ and $\mathrm{Cu}-5 \cdot 3 \mathrm{Al}$ indicates that $\sigma_{d}$ is about $40 \%$ higher than the static flow stress (Tirupataiah and Sundararajan 1990). Thus, solid solution strengthening in the case of copper is equally effective even at high strain rates of the order of $10^{4} / \mathrm{s}$.

The high strain rate hardness $\left(H_{d}\right)$-strain curves of iron (HV77) and a steel of hardness HV260 are presented in figures $8 \mathrm{a}$ and $\mathrm{b}$. These materials show an initial strain-hardening portion followed by a strain-softening regime. A detailed analysis of these curves described elsewhere (Tirupataiah and Sundararajan 1990) points to localization of plastic flow as being responsible for strain softening. This form of localization, though peculiar to the DI technique, does occur during solid particle erosion and ballistic penetration and thus has engineering relevance. A comparison of the hardening portion of the dynamic hardness-strain curves (after converting it to the uniaxial flow stress) of iron and HV260 steel with the corresponding static flow stress values (not given here) indicates that the dynamic flow stress values are about $250 \%$ and $30 \%$ higher for iron and steel respectively. The extremely high strain rate sensitivity of iron is due to the dominance of the Peierls-Nabarro mechanism for dislocation motion at high strain rates.

In the case of steel, though it is stronger than iron by a factor of 3.4 at static strain rates (in terms of static hardness), at dynamic strain rates it is stronger only by a factor of $1 \cdot 75$. Steels with higher hardness show a similar trend (Tirupataiah and Sundararajan 1990). Thus the strengthening of steels by quenching and tempering is less effective at high strain rates when compared to static strain rates.

Now turning to the literature data, figure 9 shows the variation of the flow stress 

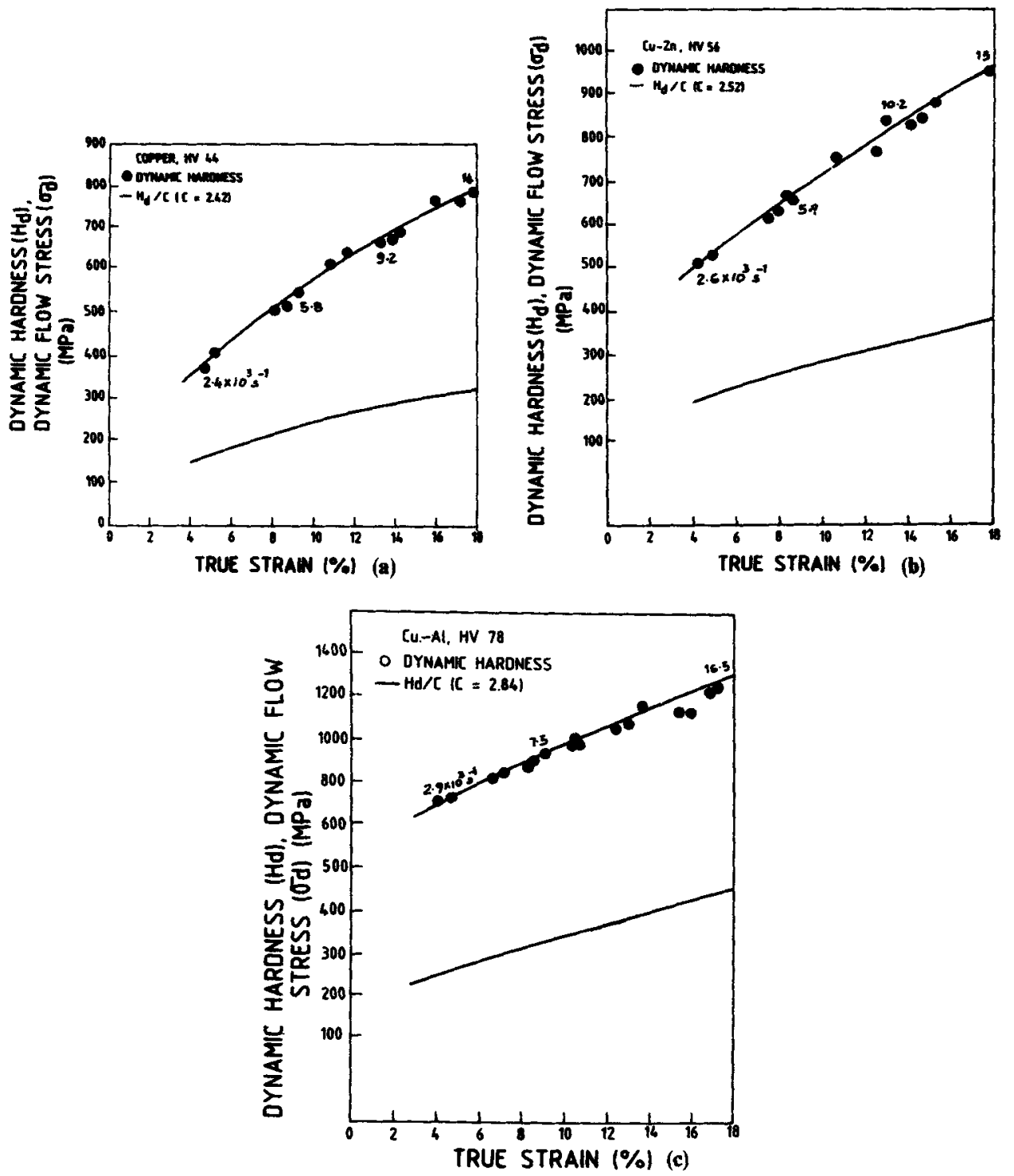

Figure 7. Variation of the dynamic hardness with true strain (filled circles) obtained using the DI technique in the case of (a) copper, (b) copper-20 zinc and (c) copper-5.3 aluminium. The full lines without data points in these figures represent the equivalent uniaxial flow stress-strain curves obtained by dividing the hardness by the constraint factor $(\mathrm{C})$.

with strain rate in the case of 304 stainless steel (Stout and Follansbee 1986) and Ti-6Al-4V alloy (Follansbee and Gray 1989). The flow stress of both these materials exhibits logarithmic strain rate sensitivity up to a strain rate of $10^{2} / \mathrm{s}$. Beyond this strain rate, the flow stress appears to increase more dramatically with strain rate. The strain rate sensitivity of non-metallic materials has also been characterized by various investigators. Figure 10 shows one such example. In this figure the variation of yield strength of a number of engineering ceramics like silicon carbide, silicon nitride, alumina and partially-stabilized zirconia as a function of strain rate is depicted 

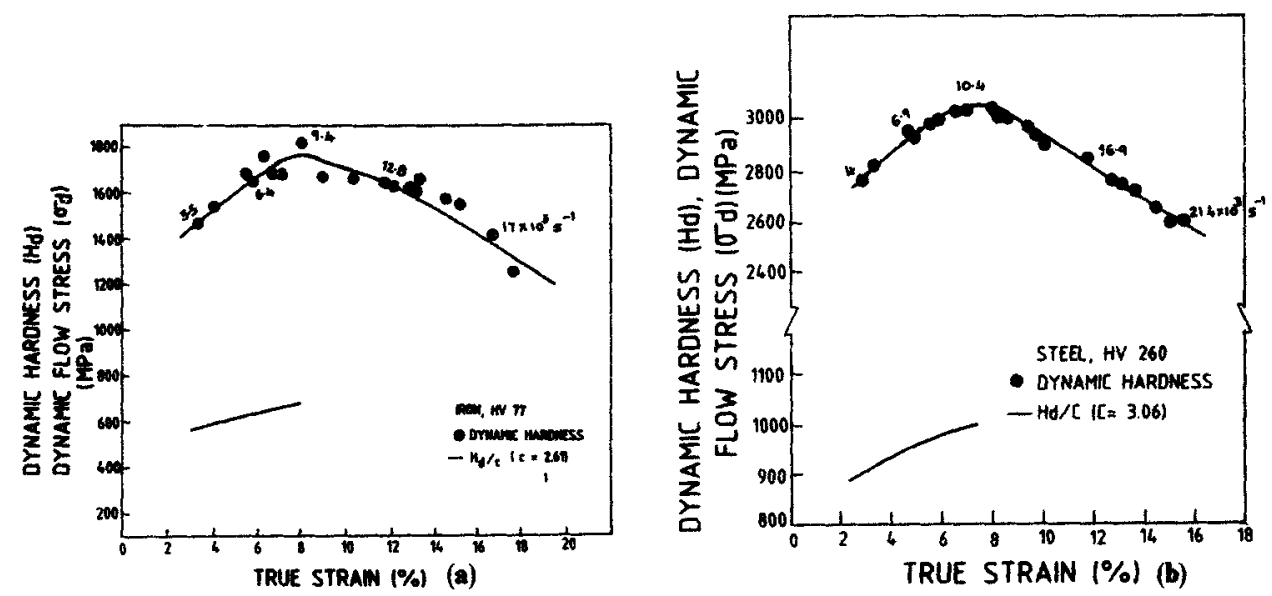

Figure 8. Variation of the dynamic hardness with the true strain (filled circles) obtained using the DI technique in the case of iron (a) and steel of hardness HV260 (b). The full lines without data points represent the equivalent uniaxial fow stress-strain curves.

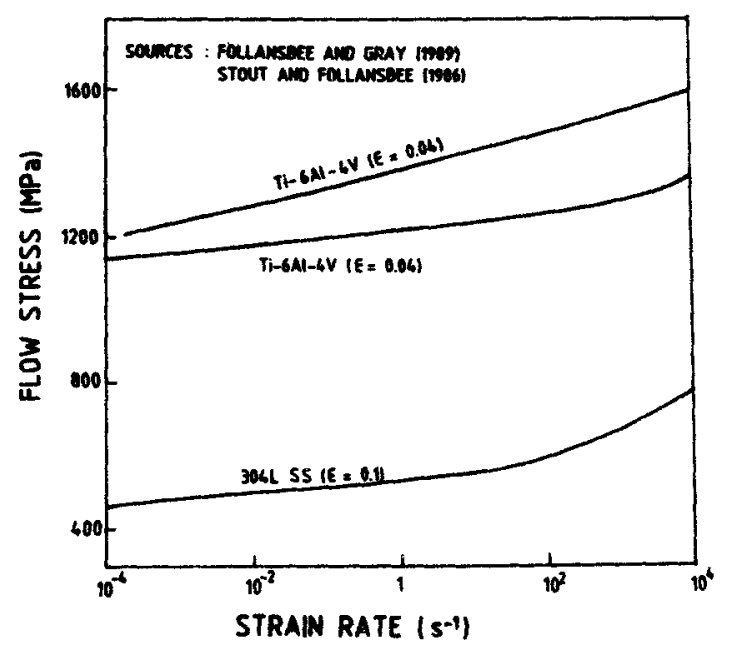

Figure 9. Variation of flow stress with strain rate in the case of 304 stainless steel and Ti-6Al-4V alloy.

(Ritter et al 1986). These materials, just like metallic materials, show a dramatic increase in strain rate sensitivity at very high strain rates in the range $10^{2}$ to $10^{3} \mathrm{~s}^{-1}$. The strain rate dependence of the maximum stress in the case of concrete (figure 11) is however markedly different (Malvern et al 1985).

A perusal of figures 2,9 and 10 clearly indicates that in many metallic materials and ceramics there is a tendency for the flow stress (or yield strength) to increase dramatically at high strain rates. In fact, a transition strain rate, beyond which the flow stress increases sharply with strain rate can be defined. Based on a comprehensive analysis of the literature data, Tirupataiah and Sundararajan (1990) were able to estimate this transition strain rate for a number of metals and alloys covering a wide range with respect to strength. The data so obtained presented in figure 12 indicate 


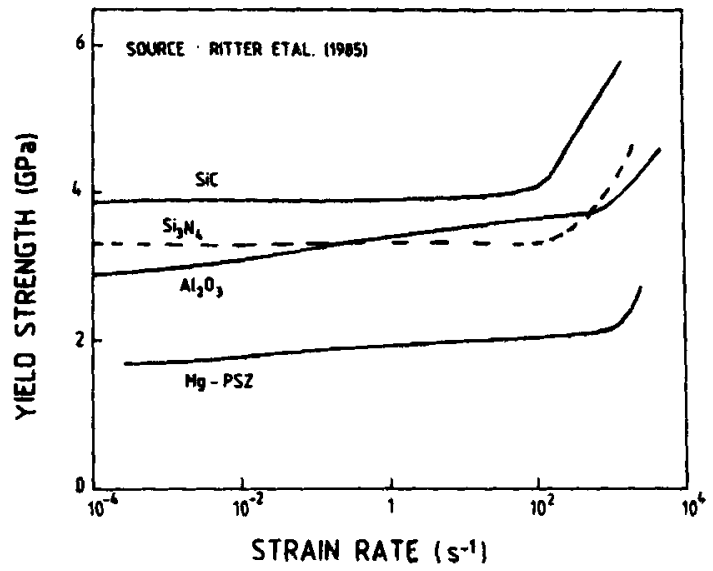

Figure 10. Strain rate dependence of yield strength exhibited by the typical engineering ceramics.

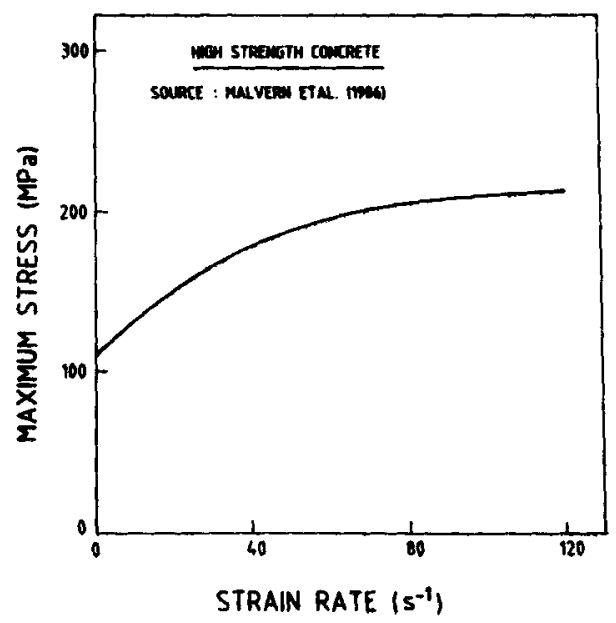

Figure 11. Variation of the maximum stress with strain rate in the case of a high strength concrete.

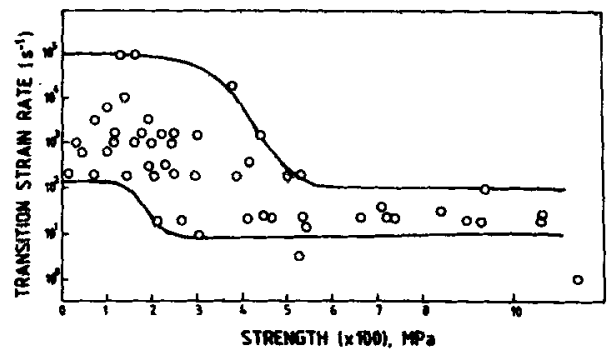

Figure 12. A compilation of the transition strain rate of a number of metals and alloys as a function of their strength. 
that the transition strain rate decreases with increasing strength of the material to values as low as $10 / \mathrm{s}$. Thus, the transition strain rate is very much a material-dependent parameter.

Over the last few years, a controversy has arisen regarding the nature of the dislocation mechanism responsible for plastic flow at high strain rates beyond the transition strain rate. Till a few years back, the strong strain rate sensitivity at high strain rates was associated with a transition from a thermally activated to a viscous mechanism (Kumar et al 1968; Muller 1971). However, a detailed analysis carried out recently in the case of copper (Follansbee and Kocks 1988) has clearly shown that even at strain rates up to $10^{5} / \mathrm{s}$, the experimentally observed flow stress is below the mechanical threshold (equation (16)) thus ruling out the viscous mechanism. The strong strain rate sensitivity at high strain rates can then be explained within the framework of the thermally-activated mechanism (equation (14)) by assuming the thermal component of the mechanical threshold $\left(\hat{\sigma}_{\mathrm{th}}\right)$ to be strain rate-sensitive at high strain rates. Recent work at DMRL on iron and copper has confirmed the above findings (Tirupataiah and Sundararajan 1990). On the basis of extensive experimental work at both low and high strain rates and a few selected experiments at sub-zero (up to $77 \mathrm{~K}$ ) and elevated temperatures, the various parameters pertinent to the thermally activated deformation mechanism defined in equation (14), have been evaluated for iron and copper. The values of these parameters are listed in table 2.

Table 2 indicates that the normalized activation energy $\left(g_{0}\right)$ in the case of iron and copper equals $0 \cdot 1$ and $0 \cdot 16$ respectively. These values correspond to an activation energy of 0.6 and $1.0 \mathrm{eV}$ respectively. A value of $0.6 \mathrm{eV}$ for iron, along with $p=1 / 2$ and $q=1$ is consistent with the Peierls-Nabarro lattice friction mechanism. In contrast, an activation energy of $1 \mathrm{eV}$ and $p=2 / 3$ and $q=1$ obtained for copper is consistent with a mechanism involving the cutting of forest dislocations.

Utilizing the parameter values provided in table 2 and (14), the variation of flow stress $\left(\sigma_{f}\right)$ as well as its thermal $\left(\sigma_{\mathrm{th}}\right)$ and athermal $\left(\sigma_{\mathrm{ath}}\right)$ components can be computed as a function of temperature or strain rate. The results of such a computation, for iron and copper are respectively illustrated in figures 13 and 14. An interesting aspect of figures 13 and 14 is that, in contrast to copper, the thermal component is substantial in iron especially at low temperatures or high strain rates. Figures 14 and 15 also

Table 2. Values of the various parameters defined by equation (14) for iron and copper.

\begin{tabular}{lccc}
\hline & & \multicolumn{2}{c}{ Values } \\
\cline { 3 - 4 } Parameter & Units & Iron* & Copper** \\
\hline$\dot{\varepsilon}_{0}$ & $\mathrm{~s}^{-1}$ & $10^{7}$ & $10^{7}$ \\
$P$ & - & 0.5 & 0.66 \\
$q$ & - & 1.0 & 1.00 \\
$g_{0}$ & - & 0.10 & 0.154 \\
$\hat{\sigma}_{\text {th }}\left(<10^{3} / \mathrm{s}\right)$ & $\mathrm{MPa}$ & 626 & 77 \\
$\sigma_{\text {ath }} / G\left(10^{-3}\right)$ & - & 3.906 & 3.842 \\
$G(\mathrm{RT})$ & $\mathrm{GPa}$ & 64.0 & 42.2 \\
$G(0 \mathrm{~K})$ & $\mathrm{GPa}$ & 72.6 & 47.20 \\
$b \times 10^{10}$ & $\mathrm{~m}$ & 2.48 & 2.56 \\
\hline
\end{tabular}

$*$ at $5 \%$ strain; ** at $10 \%$ strain 

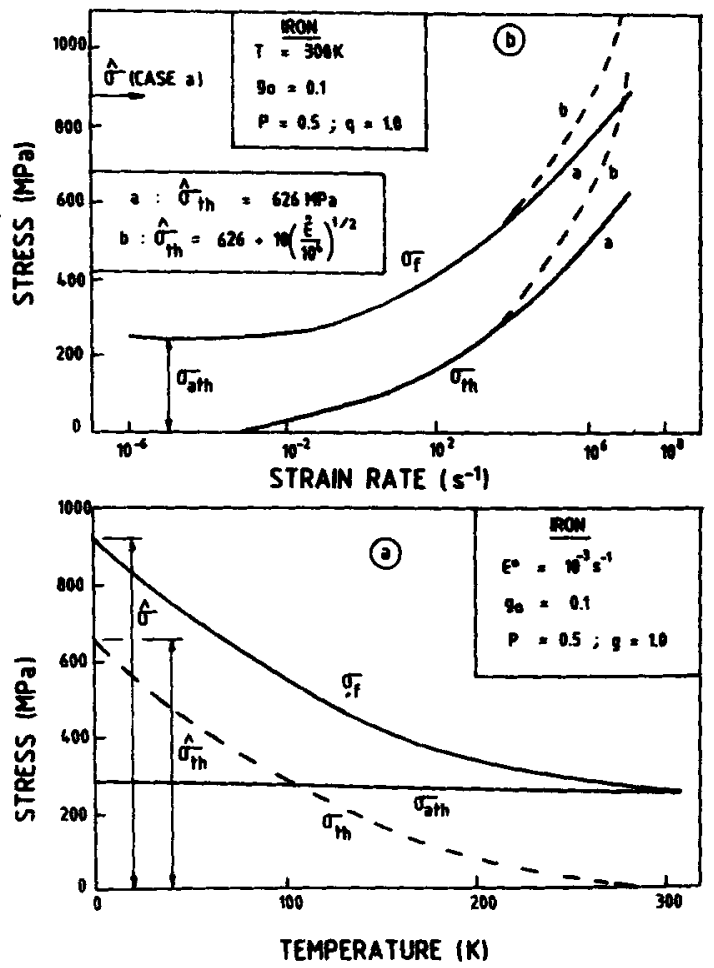

Figure 13. Variation of the flow stress $\left(\sigma_{f}\right)$ of iron and its athermal $\left(\sigma_{\mathrm{ath}}\right)$ and thermal $\left(\sigma_{\mathrm{th}}\right)$ components with (a) temperature (strain rate $=10^{-3} \mathrm{~s}^{-1}$ ) and (b) strain rate $(T=300 \mathrm{~K}$ ). These curves have been calculated using the data in table 2 . The dashed lines in (b) illustrate the effect of a strain rate-dependent mechanical threshold on the flow stress of iron and its thermal component.

illustrate the fact that the total mechanical threshold $(\hat{\sigma})$ is higher than the flow stress $\left(\sigma_{f}\right)$ even at a strain rate of $10^{4}$ or $10^{5} / \mathrm{s}$. In fact, the use of $\dot{\varepsilon}_{0} \simeq 10^{7} / \mathrm{s}$ in (14) implies that the strain rate should be $10^{7} / \mathrm{s}$ before viscous drag mechanism becomes rate-controlling. Such high strain rates are usually achieved in a material when it is shock-loaded.

Figures 13 and 14 also illustrate how a dramatic increase in the flow stress with strain rate beyond the transition strain rate can be obtained within the framework of the thermally-activated mechanism. If the thermal component of the mechanical threshold $\left(\hat{\sigma}_{t h}\right)$ is assumed to be strain rate-insensitive (case a), the flow stress increases with strain rate in a logarithmic fashion all the way up to a strain rate of $10^{7} / \mathrm{s}$ as shown in figures 13 and 14 . In contrast, if $\hat{\sigma}_{\mathrm{th}}$ is assumed to be strain rate-sensitive (case b), as can be seen in figures 13 and 14, a dramatic increase in the flow stress with strain rate at high strain rates can be predicted. Thus, the concept of transition strain rate also becomes valid.

Finally, equation (14), as well as figures 13 and 14, bring out the fact that the high strain rate deformation is not equivalent to low temperature deformation as usually assumed. In fact, the equivalence of high strain rate and low temperature deformation is possible only when 


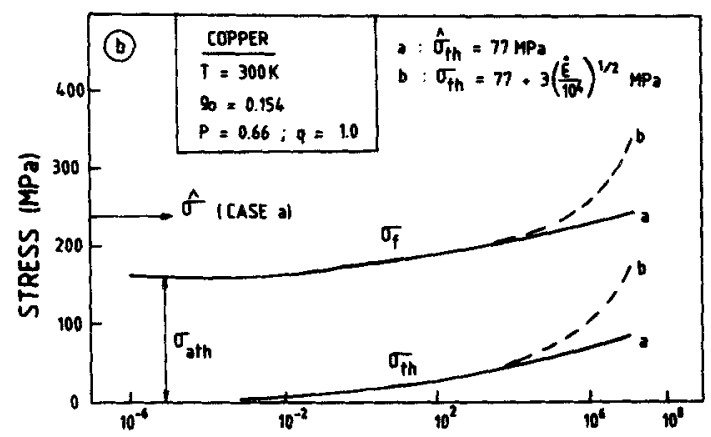

STRAIN RATE $\left(\mathrm{s}^{-1}\right)$

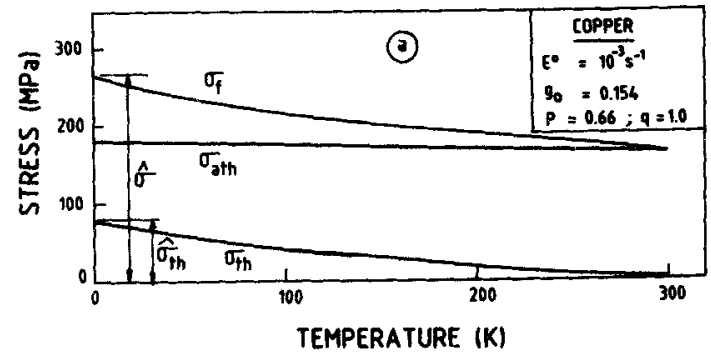

Figure 14. Variation of the flow stress $\left(\sigma_{f}\right)$ of copper and its athermal $\left(\sigma_{\text {ath }}\right)$ and thermal $\left(\sigma_{\mathrm{tb}}\right)$ components with (a) temperature (strain rate $=10^{-3} \mathrm{~s}^{-1}$ ) and (b) strain rate $(T=300 \mathrm{~K})$. These curves have been calculated using the data in table 2 . The dashed lines in (b) illustrate the influence of a strain rate-dependent mechanical threshold on the flow stress of copper and its thermal component.

(a) the flow stress at low temperature and high strain rate is mostly due to the thermal component (i.e. $\sigma_{f}=\sigma_{\text {th }}$ in figures 13 and 14) and

(b) the mechanical threshold is independent of strain rate at all the strain rates (i.e. case $a$ in figures 13 and 14).

If conditions a and b are satisfied then the parameter " $T \ln \dot{\varepsilon}_{0} / \dot{\varepsilon}$ " in (14) describes the equivalence.

\subsection{Summary}

In this section, the various aspects of plastic deformation at high strain rates have been reviewed. It has been shown that all materials have equivalent or higher strength under high strain rate deformation conditions characteristic of dynamic loading. Thus, design of structures based on static strength values, though conservative, is most probably adequate. However, as will be shown in the next section, the fracture toughness of many materials may be lower under dynamic loading conditions.

\section{Fracture behaviour of materials at high loading rates}

\subsection{Introduction}

As in the case of deformation studies, most work in fracture mechanics so far has been concentrated on fracture under static loading conditions. In situations which 
call for design for fracture resistance in the presence of impulsive loads, knowledge of fracture toughness of the structural materials under high loading rates is required. This requirement has led in recent years to the development of dynamic fracture mechanics concepts. Here, we shall briefly discuss some of the basic concepts of dynamic fracture mechanics and the techniques used for dynamic fracture toughness evaluation. The influence of metallurgical variables on dynamic fracture toughness of materials will also be considered.

\subsection{Dynamic fracture mechanics}

It might be thought that the term dynamic fracture mechanics applies only to those fracture problems in which inertia forces must be included in the equations of motion of the body. While such problems are certainly included, the subject is actually much broader. It encompasses all fracture mechanics problems where either the load or the crack size changes rapidly regardless of whether or not inertia forces become significant. It follows that any time-dependent boundary value problem addressing rapid crack initiation, propagation and/or arrest lies within the domain of dynamic fracture mechanics. In practice, two kinds of dynamic fracture mechanics problems have received most attention. These are:

(a) bodies with stationary cracks that are subjected to a rapidly varying load, and

(b) bodies that contain a rapidly moving crack.

At present, as in all other branches of fracture mechanics, the bulk of the applications in dynamic fracture mechanics assumes linear elastic conditions. Current research efforts are focussed on incorporating elastic-plastic behaviour into dynamic treatments. Two points of view on dynamic fracture mechanics are extant: continuum-based and micromechanical-based. Except for one dominant crack-like defect, the former view generally assumes the material to be continuous. The latter, in contrast, considers the failure process to develop from the initiation, growth and coalescence of a great many random material imperfections. In this paper we shall emphasize the continuum linear elastic view, consistent with by far the most research and application work in the field.

As stated above in elastodynamic fracture one has to consider two counterparts of static fracture toughness of materials. First, for the onset of growth a a rapidly loaded stationary crack, we have

$$
K=K_{\mathrm{Id}}(\dot{\sigma})\left[\text { or } K=K_{\mathrm{Id}}(\dot{K})\right],
$$

where $K$ is the dynamic stress intensity factor and $K_{\mathrm{Id}}$ is the dynamic initiation fracture toughness which unlike the static fracture toughness $K_{\mathrm{IC}}$ is not just a material property but also depends upon the loading rate.

Second, for dynamically-propagating cracks under quasi-static or dynamic loading conditions, it has been suggested that crack propagates when

$$
K=K_{\mathrm{ID}}(\dot{a}) \text {, }
$$

where $\dot{a}$ is the crack velocity and $K_{\mathrm{ID}}$ is the dynamic propagation fracture toughness. According to this criterion, crack arrest occurs when the instantaneous dynamic stress intensity factor becomes less than or equal to a critical value, that is when

$$
K \leqslant K_{\mathrm{ID}}(0)=K_{\mathrm{la}},
$$


where $K_{\mathrm{la}}$ denotes the dynamic crack arrest toughness. Until recently, quasi-static analyses were used to determine the dynamic stress intensity factors. However, the development of optical techniques such as caustics and photoelasticity, and nonoptical techniques such as dynamic strain gauge technique and numerical finite element method have made calculation of actual dynamic stress intensity factors much easier.

We shall now discuss some of the commonly used test procedures for measuring $K_{\mathrm{Id}}$ and $K_{\mathrm{la}}$.

\subsection{Experimental determination of dynamic fracture toughness}

(a) Cracks under impact loading ( $K_{I d}$ determination): The dynamic fracture initiation toughness $K_{I d}$ is usually determined with precracked bend specimens in instrumented impact tests. The specimens are loaded by a drop weight or by a pendulum type impact tester. Loading rates between $10^{2} \mathrm{MPa} \sqrt{m} / \mathrm{s} \leqslant \dot{K} \leqslant 10^{5} \mathrm{MPa} \sqrt{m} / \mathrm{s}$ can be achieved using such machines. The instrumented charpy test is by far the most popular technique for $K_{I d}$ determination. This technique has practical advantages such as small specimen size, low preparation cost and relatively simple apparatus. A standard charpy V-notch specimen $(10 \times 10 \times 55 \mathrm{~mm})$ with a fatigue pre-crack can be used for $K_{\text {Id }}$ determination. The single most important piece of information from this type of test is the load-time signal obtained from the strain gauges at the instrumented tup. The load-time plots obtained for some of the materials tested in DMRL such as mild steel, tungsten-based heavy alloys and FRP composites are illustrated in figures 15a, $\mathrm{b}$ and $\mathrm{c}$, respectively. It can be seen that different materials exhibit different load-time
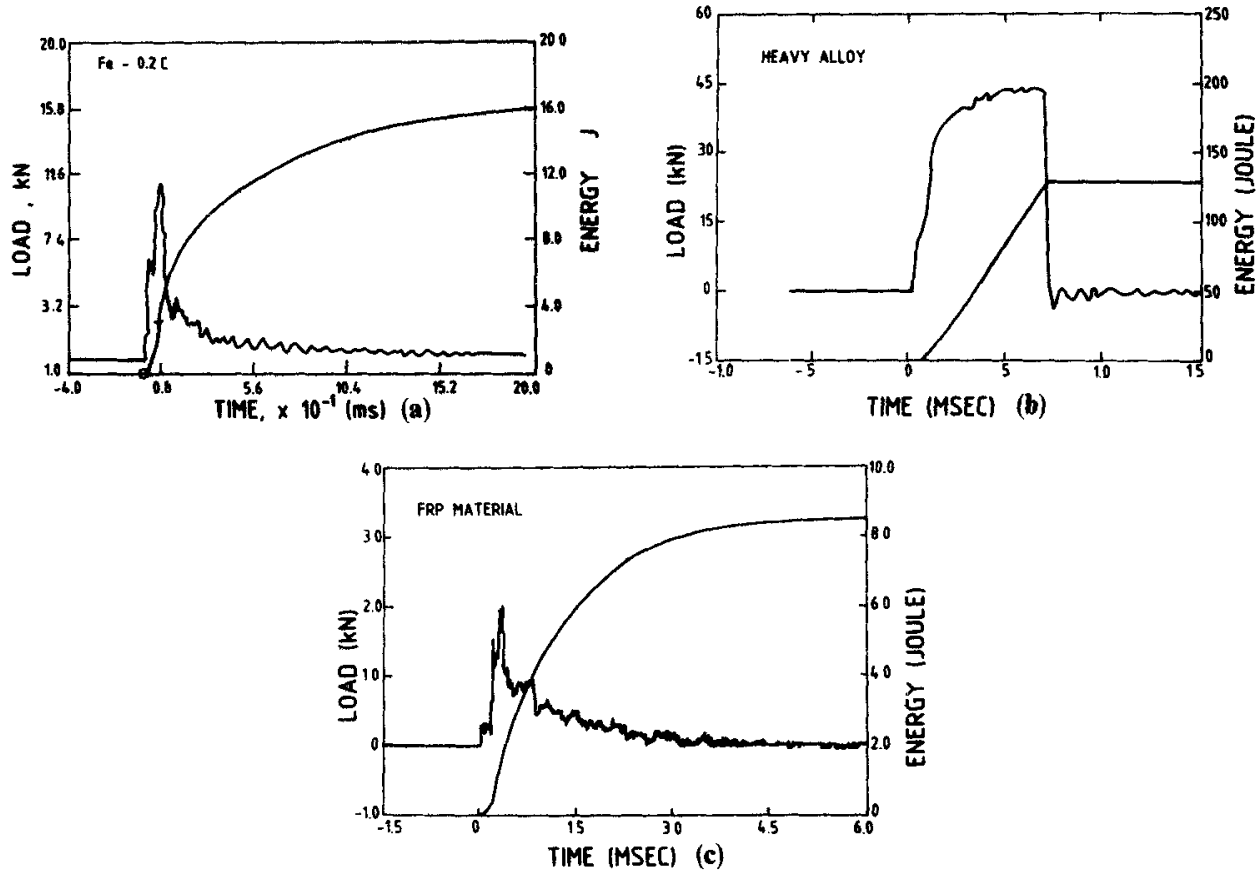

Figure 15. Representative load-time plots obtained from an instrumented charpy test for (a) mild-steel, (b) tungsten based heavy alloy and (c) FRP composites. 
behaviours. Crack initiation is assumed to occur at maximum load whereas crack propagation controls the subsequent load-time behaviour. It can be observed that tungsten-based heavy alloys and mild steel have good crack initiation resistance but low crack propagation resistance whereas FRP composites have low initiation but moderate crack propagation resistance.

The maximum load is then used in a quasi-static formula for stress intensity factor $K$ to get $K_{\text {Id }}$.

$$
K_{\mathrm{Id}}=\frac{6 Y P L}{4 B w^{2}}(a)^{1 / 2}
$$

where $Y$ is the geometry factor, $P$ the maximum load, $L$ the span length, $a$ the crack length, $B$ the specimen thickness and $w$ the specimen width. $K_{\text {Id }}$ obtained is then verified for dimensional check according to ASTM E-399 using the expression,

$$
B, a \geqslant 2 \cdot 5\left(K_{\mathrm{Id}} / \sigma_{\mathrm{yd}}\right)^{2},
$$

where $\sigma_{\mathrm{yd}}$ is the dynamic yield strength. However, in recent years several investigators have shown that one can use quasi-static analysis only under very restrictive conditions because dynamical effects are quite appreciable in a charpy specimen due to its small size. It is suggested that $K_{\text {Id }}$ calculated from such quasi-static analysis is valid only if the time of fracture $\left(t_{f}\right)$ is greater than three times the mean oscillation time $(\tau)$ associated with the inertia of the specimen. To avoid this problem the current trend is to measure the dynamic stress intensity factor directly. The optical techniques of caustics (Manogg 1966; Beinert and Kalthoff 1981; Rosakis et al 1983; Kalthoff 1985) and photoelasticity (Bradley and Kobayashi 1970; Dally 1979; Irwin 1979; Sanford and Dally 1979; Kobayashi and Dally 1980) are the techniques in vogue because of their relative simplicity and the ease with which dynamic fracture mechanics parameters of interest can be determined from the experimentally recorded data.

The importance of obtaining $K_{\mathrm{Id}}$ using dynamic analysis for the stress intensity factor rather than quasi-static analysis is illustrated in figure 16 (Kalthoff 1985) which

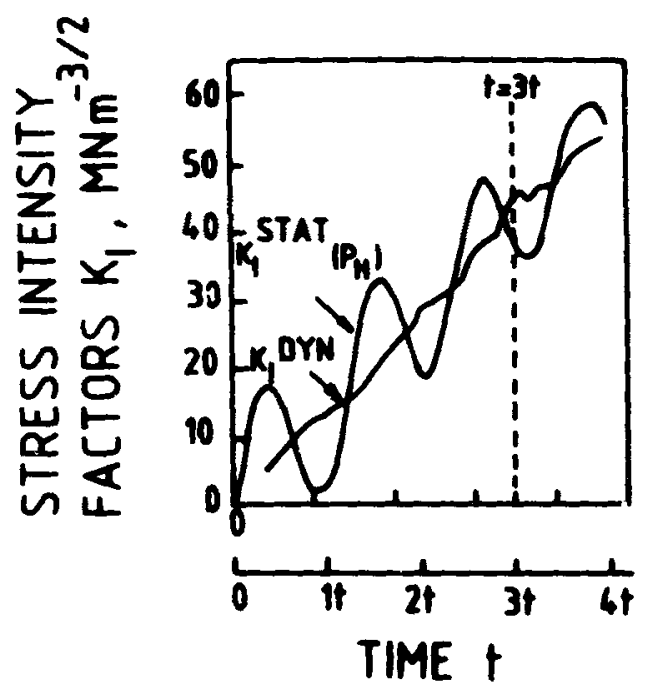

Figure 16. Variation of $K_{\mathrm{l}}^{\text {stat }}$ and $K_{\mathrm{l}}^{\mathrm{dyn}}$ with time in high strength steel. 
shows the variation of $K_{1}^{\text {stat }}$ and $K_{1}^{\text {dyn }}$ with time in a high strength steel. It can be observed that depending upon the time of crack initiation, $K_{l d}$ calculated using static analysis can either overestimate or underestimate the actual dynamic fracture toughness of the material.

(b) Crack arrest fracture toughness $\left(K_{l a}\right)$ determination: The usual procedure for measuring crack arrest fracture toughness involves initiating a rapidly propagating crack from a blunted initial notch at an initiation stress intensity factor $K_{\mathrm{Iq}}>K_{\mathrm{IC}}$, in a wedge-loaded specimen. A double cantilever beam (DCB) or a single edge notch (SEN) specimen is most commonly used for $K_{\mathrm{la}}$ determination. A DCB specimen under longitudinal wedge loading is illustrated in figure 17a. The crack-opening displacement remains constant during crack propagation due to the stiffness of the loading system. Thus the crack propagates into a decreasing stress intensity factor field. It arrests at length $a$ if the conditions for crack propagation are not fulfilled

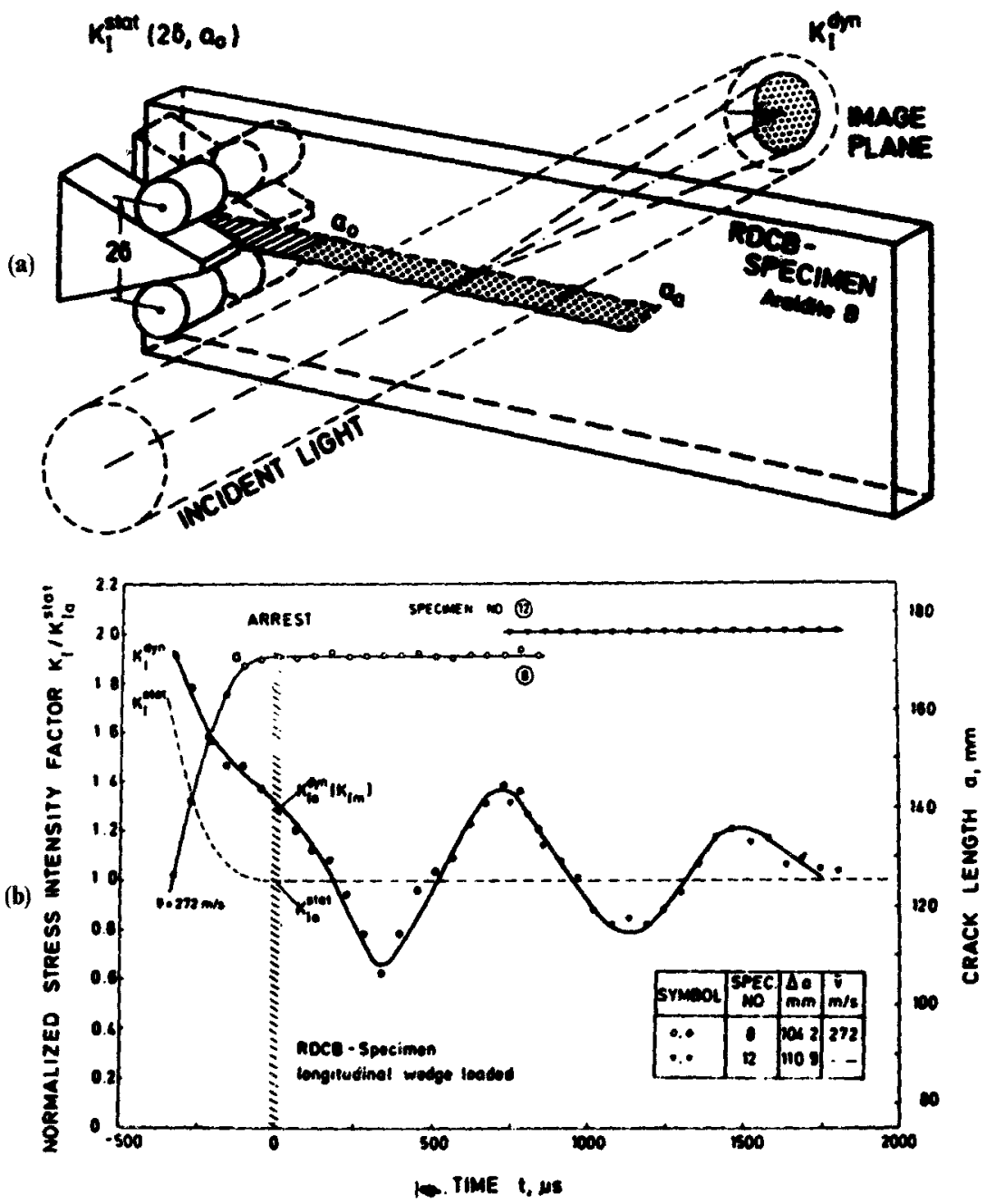

Figure 17. (a) Double cantilever beam specimen under wedge loading and (b) variation of normalized stress intensity factor $K_{\mathrm{l}} / K_{\mathrm{la}}^{\text {stat }}$ with time. 
any more. The stress intensity factor at arrest represents $K_{\mathrm{ja}}$ and it can be calculated by either quasi-static formula, or by experimental techniques such as caustic, or photoelasticity.

Statically determined crack arrest toughness values $K_{\mathrm{la}}^{\text {stat }}$ are smaller than the true dynamically determined crack arrest toughness $K_{1 \mathbf{a}}^{\mathrm{dyn}}$. This is illustrated in figure $17 \mathrm{~b}$ (Kanninen 1985). However, it should be noted that in large-scale structures where dynamic effects are generally less than in relatively smaller laboratory-test specimens which are used for $K_{\mathrm{Ia}}$ determination, quasi-static crack arrest analysis will yield conservative crack arrest predictions.

\subsection{Effect of metallurgical factors on dynamic fracture toughness of materials}

It is generally agreed that in the $10^{2} \mathrm{MPa} \sqrt{m} / \mathrm{s} \leqslant \dot{K} \leqslant 10^{6} \mathrm{MPa} \sqrt{\mathrm{m}} / \mathrm{s}$ regime, the dynamic fracture toughness in lower than the static fracture toughness for materials which undergo strain-rate hardening. Thus, in most cases, for structures which are susceptible to high loading rates one has to design based on dynamic fracture toughness rather than the static fracture toughness. Unfortunately, very little is known about how metallurgical factors influence the dynamic fracture toughness.

It is generally assumed that the metallurgical factors will influence dynamic fracture toughness in the same way as they influence the static fracture toughness. A recent study at DMRL (Srinivas et al 1991a) has shown that the static fracture toughness of Armco iron increases with decreasing grain size and the variation can be expressed by a relationship similar to that for Hall-Petch for strength as

$$
J_{1 \mathrm{c}}=52+40 \cdot 5 d^{-1 / 2}
$$

where $J_{\mathrm{lc}}$ is in $\mathrm{kJ} / \mathrm{m}^{2}$ and $d$ in $\mathrm{mm}$.

A study was carried out to investigate the effect of grain size on dynamic fracture toughness $\left(J_{\text {Id }}\right)$ of Armco iron. Various thermomechanical treatments were used to produce grain sizes of $38,78,252,657$ and $1050 \mu \mathrm{m}$, respectively. Dynamic fracture toughness tests were done on EDM notched (notch root radius $80 \mu \mathrm{m}$ ) charpy specimens using instrumented pendulum type machine. The results obtained are listed in table 3 . It can be seen that there is limited influence of grain size on $J_{\text {ld }}$ (figure 18). This observation is further corroborated in figure 19 which shows limited variation of dynamic hardness with strain for the different grain sizes (Srinivas 1991).

The effect of solute additions on dynamic fracture toughness has also been studied

Table 3. Dynamic fracture toughness data on Armco iron.

\begin{tabular}{lc}
\hline $\begin{array}{l}\text { Grain size } \\
(\mu \mathrm{m})\end{array}$ & $\begin{array}{c}J_{\text {Id }} \\
\left(\mathrm{KJ} / \mathrm{m}^{2}\right)\end{array}$ \\
\hline 38 & 1250 \\
78 & 1220 \\
252 & 1150 \\
657 & 1145 \\
1050 & 1150 \\
\hline
\end{tabular}




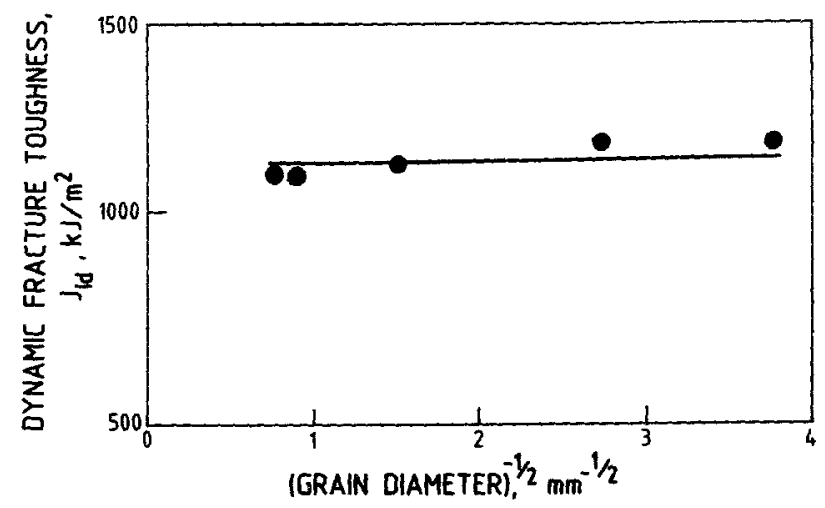

Figure 18. Variation of dynamic fracture toughness $\left(J_{\mathrm{Id}}\right)$ with grain size.

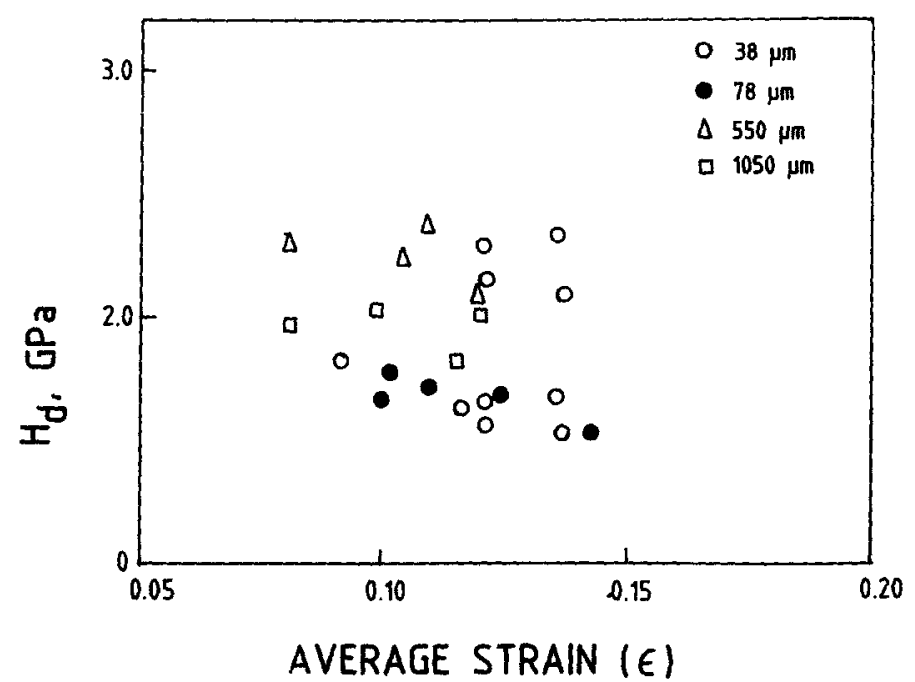

Figure 19. Variation of dynamic hardness with average strain for different grain sizes.

(Srinivas et al 1991b) Srinivas et al observed that 5\% addition of cobalt to $0.2 \% \mathrm{C}$ mild steel affects the static fracture toughness but not the dynamic fracture toughness, whereas a $5 \%$ addition of nickel to $0.2 \% \mathrm{C}$ mild steel results in a significant increase in the dynamic fracture toughness but not the static fracture toughness. Representative load-time plots for $\mathrm{Fe}-0.2 \% \mathrm{C}, \mathrm{Fe}-0.2 \% \mathrm{C}-5 \% \mathrm{Co}$ and $\mathrm{Fe}-0.2 \% \mathrm{C} 5 \% \mathrm{Ni}$ are illustrated in figures $20 \mathrm{a}, \mathrm{b}$ and $\mathrm{c}$, respectively. The improvement in dynamic fracture toughness with nickel additions is attributed to the fact that at high strain rates it causes softening in the alloy (Srinivas 1991).

Thus based on the above results it is evident that the influence of metallurgical factors on dynamic fracture toughness need not be the same as their influence on static fracture toughness. More research needs to be done in this area to quantify the influence of metallurgical variables on the dynamic fracture toughness. 

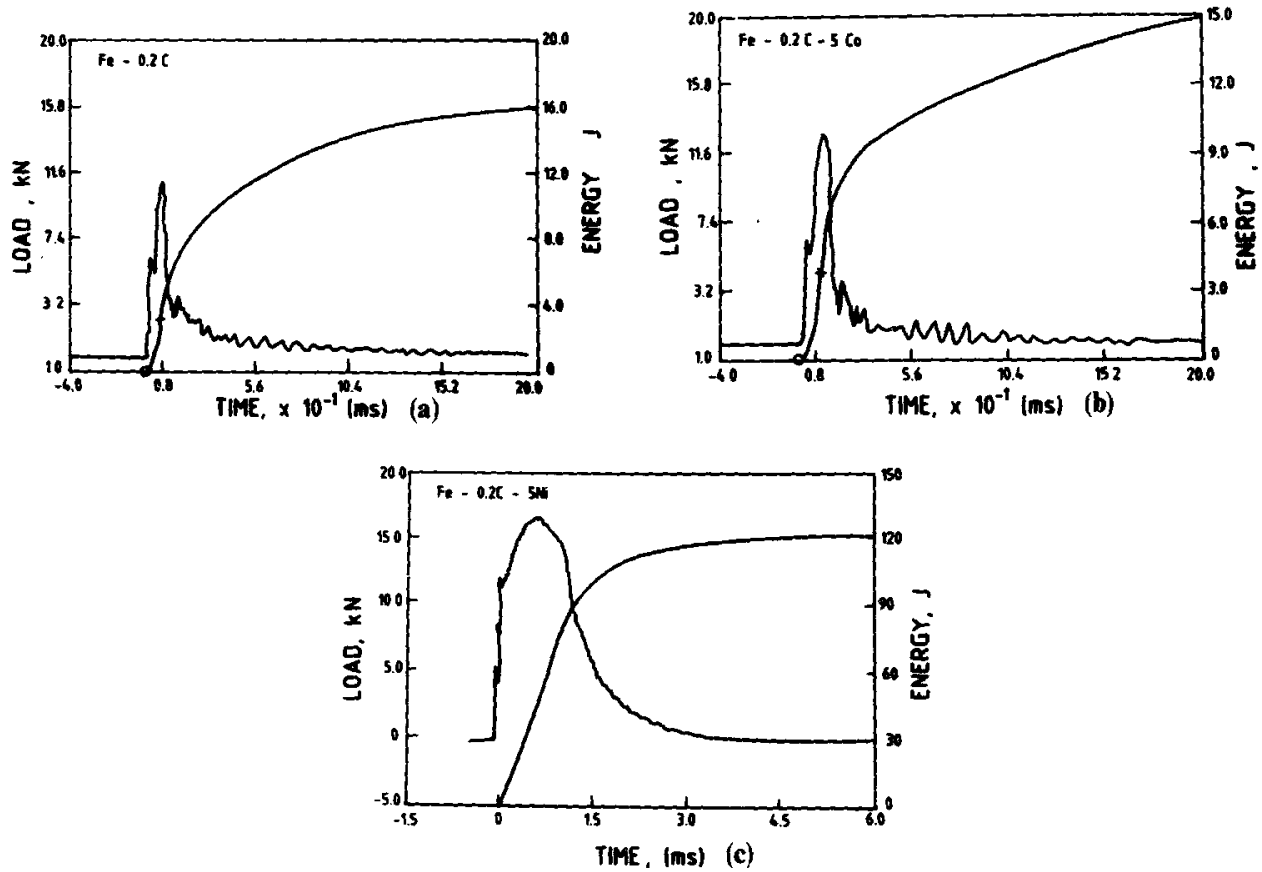

Figure 20. Load-time plots obtained from an instrumented charpy test for (a) $\mathrm{Fe}-0-2 \% \mathrm{C}$, (b) $\mathrm{Fe}-0.2 \% \mathrm{C}-5 \% \mathrm{Co}$, (c) $\mathrm{Fe}-0.2 \% \mathrm{C}-5 \% \mathrm{Ni}$.

\section{Conclusions}

Dynamic fracture mechanics concepts should be used in designing structures which are susceptible to high loading rates. Although standard techniques are not available for dynamic fracture toughness measurements, there are well established tests for both $K_{\mathrm{Id}}$ and $K_{\mathrm{Ia}}$ measurements. Further work needs to be done to study the ways of improving the dynamic fracture toughness of structural materials. Also there is scope for introducing mixed mode concepts when considering dynamic crack initiation and propagation fracture toughness as in several cases, cracks are found to deflect or branch under dynamic loading conditions.

\section{References}

Baker W E and Yew C H 1966 J. Appl. Mech. 33917

Beinert $J$ and Kalthoff J F 1981 Mechanics of fracture (ed.) G C Sih (Leyden, The Netherlands: VII Nordhoff Int. Publishing)

Bradley W B and Kobayashi A S 1970 Exp. Mech. 10106

Briggs T L and Campbell J D 1972 Acta Metall. 20711

Dally J W 1979 Expr. Mech. 19349

Follansbee P S 1985 Metals handbook 9th edition (Ohio: American Society for Metals) p. 198

Follansbee P S and Kocks U S 1988 Acta Metall. 3681

Follansbee P S and Gray G T 1989 Metall. Trans. A20 863

Follansbee P S 1986 Metallurgical applications of shockwave and high strain rate phenomena (eds) L E Murr, K P Staudhammer and M A Meyers (New York: Marcel Dekker) p. 451

Frantz R A and Duffy J 1972 J. Appl. Mech. 39939 
Hawkyard J B, Eaton D and Johnson W 1968 Int. J. Mech. Sci. 10929

Hoggatt C R and Recht R F 1969 Exp. Mech. 9441

Hopkinson B 1914 Philos. Trans. A213 441

Irwin G R 1979 Exp. Mech. 19121

Kalthoff J F 1985 Int. J. Fract. 27277

Kanninen M F 1985 Int. J. Fract. 27299

Klopp R W 1982 M.Sc thesis, Brown University, Providence, Rhode Island

Klopp R W, Clifton R J and Shawki T G 1985 Mech. Mater. 4375

Kobayashi T and Dally J W 1980 Crack arrest methodology and applications, (eds) G T Hahn and M F Kanninen ASTM STP 711 p. 189

Kocks U S, Argon A S and Ashby M F 1975 Progr. Mater. Sci. 19139

Kumar A, Hauser F E and Dorn J E 1968 Acta Metall. 161189

Li C H 1982 Ph.D thesis, Brown University, Providence, Rhode Island

Lindholm U S and Bessey B L 1986 Tech. Report AFML-TR-69-119 Air Force Materials Laboratory, Ohio

Lindholm U S 1971 Techniques in metals research (ed.) R F Bunshah (New York: Interscience)

Lindholm U S and Yeakley L M 1968 Exp. Mech. 81

Malvern L E, Jenkins D A, Tang T and Ross C A 1985 Proc. Second Symp. on Interaction of non-nuclear munitions with structures, Florida, p. 194

Manogg P 1966 Int. J. Fracture Mech. 2604

Muller T 1971 Acta Metall. 19691

Niordson F I 1965 Exp. Mech. 529

Ritter A P, Childs G L and Winzer S R 1986 Ceram. Eng. Sci. Proc. 91297

Rosaskis A J, Ma C C and Freund L B 1983 J. Appl. Mech. 105777

Sanford R J and Dally J W 1979 J. Eng. Fract. Mech. 11621

Srinivas M, Malakondaiah G, Armstrong R W and Rama Rao P 1991a Acta Metall. Mater. 39809

Srinivas M, Malakondaiah G and Rama Rao P 1991 b Proc. sixth Int. Conf. on Mechanical behaviour of materials, Kyoto, July 28-August 2, 1991, to be published

Srinivas M, Malakondaiah G and Rama Rao P 1991c Proc. Joint FEFG/ICF Int. Conf. on Fracture of engineering materials and structures, Singapore, August 6-8, 1991, to be published

Srinivas M 1991 Fracture behaviour of iron, iron-based solid solutions and $F e-C-X$ alloys, Ph.D. Thesis, Banaras Hindu University, submitted

Stout M G and Follansbee P S 1986 J. Eng. Material and Tech., Trans. ASME, 108 p. 344

Taylor G I 1948 Proc. R. Soc. (London) A194 200

Tirupataiah Y and Sundararajan G 1990 Unpublished work, DMRL, Hyderabad

Tirupataiah Y and Sundararajan G 1991 J. Mech. Phys. Solids 39243

Wilkins N L and Guinan N W 1973 J. Appl. Phys. 441200 